\title{
Examining Durkheim's Model of Suicide on Shirley Jackson's "The Lottery"
}

\author{
Sayed Mohammad Anoosheh ${ }^{1, a}$, Muhammad Hussein Oroskhan ${ }^{2, b^{*}}$ \\ ${ }^{1,2}$ Department of English Literature, Faculty of Humanities, Yazd University, Iran. \\ aSanoushe@yazd.ac.ir, bh.araskhan@yahoo.com
}

Keywords: Mechanical solidarity, organic solidarity, altruistic suicide, Shirley Jackson

\begin{abstract}
The beginning of twentieth century experienced significant changes affecting different parts of society. Such considerable changes not only influenced the appearance of the society but also dramatically changed the social bonds gripping different kinds of people together. In this regard, Emile Durkheim as the father modern sociology thoroughly reexamined the previously settled notion of sociology and brought about a new perspective studying the social bonds. With regard to his two main principles namely mechanical solidary and organic solidarity, he justifies the relationships among the individual within the traditional and modern society. Nevertheless, he mentioned that out of few rare situations, the individual may commit a type of suicide which is totally the consequent effect of society on individual. Hence, through this study it is tried to reconsider Shirley Jackson's "The Lottery" in the light of Durkheim's theory. In this case, it is revealed that while previously it was believed that the main character of the story is killed mercilessly by his friends and families, she has indeed committed altruistic suicide as the result of being so much integrated within the structure of the society.
\end{abstract}

\section{Introduction}

The beginning of twentieth century was accompanied by vast technological changes in every aspects of human life. The considerable scope of these changes provided a new of world of complexity. Consequentially, these drastic changes in society were reflected in the development of social relations among people, hence new social theorists began to interpret this complicated world. That being the case, the first sociological theorist who tried to shed new lights on the impact of modern world on the lives of individual was Emile Durkheim (1858-1917). He clearly expressed his viewpoint regarding the concept of sociology as follows:

Sociology is to study norms and not individual attitudes, social imperatives and not the reaction of the average man to the average man's picture of the social order. For the sociologist it is only in relation to the normative system of beliefs and to the sanctioned channels of action that individual conduct becomes meaningful. [1]

Durkheim's clear manifestation of the concept of sociology shows his special focus on the effect of rules and regulation generated by the society and the extent to which these rules are affecting the lives of individuals in the society. Therefore, for analyzing the life of any individual in society, one needs to first probe the structure of society and then examines its impact on the individual. Durkheim's initial consideration of the changes occurring in the modern society was really optimistic. He labelled the shift from the traditional society to the modern society as a shift in the manners that individuals try to connect with each other. He further asserted that changes in the modern society have gathered the people around in terms of organic solidarity rather than the previous notion of mechanical solidarity. Nonetheless, in his further examinations, he comprehended that transition of a society from the state of mechanical solidarity to organic solidarity is not at all easily done and would result in some "abnormal circumstances" [2]. One of these unusual occurrences happens in Shirley Jackson's "The Lottery". The story is centered on the act of killing someone for no particular reason. The mere act of killing can be interpreted differently if someone approaches the story from a sociological perspective. Considering the story in the light 
of Durkheim's theory of suicide, this is emphatically noted that the act of killing Mrs. Hutchinson is never a barbaric and vicious act of killing someone whereas it is a sincere sacrifice for the society namely altruistic suicide. Thus, a discussion of the story through Durkheim's sociological perspective can shed some new lights on a story which is highly read by different classes of people.

\section{Discussion}

\section{Theoretical Framework}

At the beginning of $20^{\text {th }}$ century, social life underwent a tremendous change as an immediate response to the exponential growth of the cities especially due to expansion of capitalism and industrial development. As such, academic social theorists began to reconsider the traditional account of social life not portraying the complexity of the social experience accordingly. Of central importance to such a massive notion is the explanation of deep structures existing within the possible order and disorder of social life. The sociologists eagerly searched for the patterns affecting the social relations and traditional social communities. Sociologist's critical eyes easily detected the vital links attaching the older community and the rituals together are breaking down amidst the big cities. The debate over the new social life received the attention of three classical social theorists; Emile Durkheim (1858-1917), Karl Marx (1818-1883), and Max Weber (18641920) are the ones constituted the ground of modern sociology in $20^{\text {th }}$. Of these three, the one who is mainly concerned with the effect of society on the individuals and carries the title of the father of modern sociology is Emile Durkheim [3].

Durkheim recounted society as the source of all social meaning. He deviated from the wellworn paths of previous theorists who insisted on the individual as the pivotal source of social meaning. Durkheim's first precise definition of sociology was expressed in his preface to The Rules of Sociological Method. He expressed the definition of sociology as "the science of institutions, of their genesis and of their functioning" [4]. Indeed, his definition succinctly summarizes his view presented in his previous work entitled The Division of Labour in Society. In the first two chapters of The Division of Labour, Durkheim manages to assert that that due to the development of societies from traditional to modern condition the status of societies have shifted from a basis in mechanical solidarity to one in organic solidarity. Durkheim's perspective justifies the transition from traditional society to modern society not as a malfunction generated by the modern society whereas as a change in the system of connecting different parts of modern society in comparison with the traditional society.

For Durkheim, mechanical solidarity shows a society in which each individual is situated within the intricate network of society, incidentally, the individual is led forward by the means of society and is devoid of any individualistic performance:

The social molecules that can only cohere in this one manner cannot move as a unit save in so far as they lack any movement of their own, as do the molecules of inorganic bodies. This is why we suggest that this kind of solidarity should be called mechanical. [4]

Durkheim believed mechanical solidarity shows human beings while being engaged in similar activities and relying mostly on shared beliefs and values instructed by the society. Hence, any action on the side of individual is conceived within the framework of society. Accordingly, he defines the role of individual as follows:

The individual consciousness, considered from this viewpoint, is simply a dependency of the collective type, and follows all its motions, just as the object possessed follows those which its owner imposes upon it. In societies where this solidarity is highly developed the individual [...] does not belong to himself; he is literally a thing at the disposal of society. [2] 
Approaching Durkheim's view of organic solidarity, one encounters a totally different condition entirely in contrast with the case of mechanical solidarity. When in fact, the mechanical solidarity signifies that individuals should resemble each other; the organic solidarity presumes that individuals are totally different from one another. Considering the type of mechanical solidarity, it is revealed that the individual personality is assimilated into the collective personality of society whereas in the case of organic solidarity, the individual "has a sphere of action that is peculiarly our own, and consequently a personality" [3]. In this respect, the society never strictly controls each individual's personality and performance and permits the individual to firmly establish him/her self, ergo the society aims at putting each individual in harmony rather than restricting the individual's domain of actions:

Society becomes more effective in moving in concert, at the same time as each of its elements has more movements that are peculiarly its own. This solidarity resembles that observed in the higher animals. In fact each organ has its own special characteristics and autonomy, yet the greater the unity of the organism, the more marked the individualisation of the parts. [2]

As it was discussed by Durkheim, the notion of mechanical solidarity is based upon the similarities and likeness of individuals fixed toward a particular purpose, on the other hand, the organic solidarity appeared due to complementary relation between different individuals in search of different targets. Durkheim's further examinations revealed that traditional societies are replaced by "a complex world of an elaborate division of labour"[1]. Within such complex system, Durkheim highlights the role of individual while simultaneously considering their interconnectedness. Nonetheless, the critical period which foregrounds such changes in the whole system brought along them a great deal of turmoil leading to unbalanced conditions. Having classified the normal patterns, Durkheim discusses such abnormality in this way; "In all these cases, if the division of labour does not produce solidarity it is because the relationships between the organs are not regulated; it is because they are in a state of anomie" [1]. Furthermore, he specifies that "the division of labour does not produce these [deleterious] consequences through some imperative of its own nature, but only in exceptional and abnormal circumstances" [1].

Durkheim seems unduly optimistic toward modern society in The Division of Labour. For him society takes on a functional aspect, and everything would lead to the most desirable results. Also, his optimistic view is wildly echoed in The Rules of Sociological Method; nonetheless, it seems that his perspective shifts toward a darker view of society in his following work. By the time, he writes Suicide, he is solely centered on those 'abnormal circumstances' previously labeled as rare occurrences but now considered as Durkheim's focal point. Therefore, he focuses on those principles that can lead an individual into committing suicides. Durkheim's definition of suicide varies with regard to the consequence of social integration and regulation. He categories them into four types of egoistic, altruistic, anomic and fatalist suicides. In this respect, Thorlindsson and Bjarnason (1998) have studied Durkheim's notion of suicide and carefully analyzed these four types of suicides in simple terms as follows:

Too little integration leads to a state of loneliness and egoistic suicide; Too much integration leads to altruistic suicide when the perceived interest of the social group is set above personal interests; Under regulation causes anomic suicides of individuals lost in a chaotic universe; Over regulation results in fatalistic suicides. [5]

Manifested in the above definition, one factor clearly distinguishes between individual committing suicide in the modern society as opposed to the traditional society which is the degree of individual being integrated with the society. For Durkheim, the degree of individual being integrated with the society defines two types of suicides namely egoistic and altruistic suicide:

Having designated as 'egoism' the condition in which the ego pursues its own life and is obedient only to itself, the designation 'altruism' adequately expresses the opposite 
condition, where the ego is not its own property. It is blended with something other than itself, and the goal of conduct is external to itself, that is, in one of the groups in which it participates. [5]

Durkheim's further explanation clearly defines the concept of altruistic suicide. He points out another difference between these two types of suicide in this way; "Egoistic suicides are unlikely to occur very widely in our own contemporary societies, where individual personality is increasingly freed from the collective personality" [5]. Based on Durkheim's distinction between these two types of suicides, it is clear that altruistic suicide has more often occurred in traditional society in which the individual sees himself totally within the framework of society and takes whatever role the society imposes on him/her even if it means committing suicide. In this case, committing suicide can be a highly rewarding since it means fulfilling your duty in the best possible way; "a social prestige thus attaches to suicide, which receives encouragement from this fact, and the refusal of this reward has effects similar to actual punishment, although to a lesser degree [5].

\section{Examining Durkheim's Model of Suicide on Shirley Jackson's "The Lottery"}

On June 26, 1948, a short story published in an issue of New Yorker attracted considerable attention that suddenly everybody was reading it through the whole United States. The story carried the title of "The Lottery" but totally different from the American views of lottery. Shirley Jackson herself explaining about the effect of her short story on American society commented on it in this way;

"The Lottery" was not my first published story, nor my last but I have been assured over and over that if it had been the only story I ever wrote or published, there would be people who would not forget my name. [6]

"The Lottery" can be considered as a classical work as it is always taught at any academic place which has the syllabus of American fiction included in their chart. Acknowledging its popularity among academics, it has never been under sufficient critical discussions. In this regard, Coulthard believes that "perhaps that is because the story seems such a transparent attack on blind obedience to tradition that little or no exegesis is necessary" [6]. Besides not being conducted adequate discussions on "The Lottery", no one has explored the short story from a sociological perspective. Indeed a sociological study of "The Lottery" is necessarily needed since the story is highly centered on the relationship between the individual and the society. There has always been a natural tendency to label the story as a horrific act of human being destroying his own types; even such highly caustic comments have been expressed by critics; "'The Lottery' expresses Shirley Jackson's abysmal opinion of her fellow creatures. Her simple villagers are not brainwashed victims but bloodthirsty victimizers" [6]. Nonetheless, a comment like this one rarely clarifies the principle purpose of the story which is to portray a traditional society on the verge of becoming a modern society. In this respect, no one would ever solely attack the nature of human being as corrupt and merciless whereas one would consider it as being situated in a network of ideas determining his/her path.

For Durkheim, the traditional societies were based on mechanical solidarity. The principle concept that pervades the notion of mechanical solidarity is the similarities and likeness among the different members of the society. In a like manner, the notion of similarities is shown within the story when the men are gathered together for the lotter; "Soon the men began to gather. Surveying their own children, speaking of planting and rain, tractors and taxes" [8]. Men talking about the same thing totally tallies with the concept of mechanical solidarity suggested by Durkheim. Further exploration of the story also reveals that each children as an individual tries to find his/her ways around, yet, he/she is not left on his/her own accord; "Bobby Martin ducked under his mother's grasping hand and ran, laughing, back to the pile of stones. His father spoke up sharply, and Bobby came quickly and took his place between his father and his oldest brother" [8]. As it is shown, the members of such societies are all directed toward one specific aim which fades away the concept of 
individual as a distinct human being, in other words, the sense of collective personality has totally swallowed the concept of individual personality and the individual sees himself solely within the intricate network of society. Also, women's situation in the story is noted to be the same; "The women, wearing faded house dresses and sweaters, came shortly after their menfolk" [8].

Considering "The Lottery" with regard to the concept of Durkheim's theory, one can see the traditional structure of the society in which the story takes place. For Durkheim, "It is because this particular structure enables society to hold the individual more tightly in its grip, making him more strongly attached to his domestic environment, and consequently to tradition" [2]. The traditional societies are predicated on similar activities done by different members of the society. Such activities are indeed the connecting tool of different members of society toward one specific aim. In this sense, when a society focuses on a specific act to be done which is for the betterment of the society, each and every member of the society should gladly and gratefully welcomes it or as Durkheim says "the individual has no interests of his own, he must be trained to renunciation and an unquestioned abnegation; whence come such partially spontaneous suicides" [2].

In Jackson's "The Lottery", the same concept is carried through the notion of lottery itself. The lottery is about selecting one person from the people of the society to be sacrificed for the sake of the society. Therefore, this is a holy ceremony and every one should be glad to partake in this ceremony and also hopeful to be selected as the one to be sacrificed. In this regard, the atmosphere of the beginning of the story truly matches with the content of the story as it is a joyful act; "The morning of June 27th was clear and sunny, with the fresh warmth of a full-summer day; the flowers were blossoming profusely and the grass was richly green" [8]. The lottery should be literally meant and analyzed therefore, there is no irony used in the usage of the word, lottery. In this regard, the one selected to be sacrificed should feel greatly delighted about because the aim of society is indeed the individual's aim; "We actually see the individual in all these cases seek to strip himself of his personal being in order to be engulfed in something which he regards as his true essence".

Our argument can further be corroborated by considering the situation of Old Man Warner in the story. He is known to be the oldest man alive participating in the lottery. He himself claims to have participated in the lottery for seventy seven times. He is usually deemed to be a devilish character within the story, but he is indeed the most honest person. And among all the people of the society, he is the one who most reveres the ceremony because it proves extremely advantageous for the society since he truly knows the original purpose of the lottery; "Used to be a saying about 'Lottery in June, corn be heavy soon.' First thing you know, we'd all be eating stewed chickweed and acorns. There's always been a lottery," he added petulantly" [8]. He vehemently condemns the idea of not having a lottery because in his view it would be really harmful for the society. And indeed such sacrifices have been the pillars that helped the society prosper at the old times:

Many ancient cultures believed that growing crops represented the life cycle, beginning with what one associates with the end-death. Seeds buried, apparently without hope of germination, represent death. But with the life forces of water and the sun, the seed grows, representing rebirth. [9]

Furthermore, he is shocked by the people's reaction toward the lottery; "'It's not the way it used to be.' Old Man Warner said clearly. 'People ain't the way they used to be"' [8]. The society in which the story is taking place seems to be on the verge of changing into a new society yet it still carries with it the appearance of a traditional society based on the concept of mechanical solidarity. This is highly reflected when prior to Mrs. Hutchinson's selection to be sacrificed, a girl wishes that Nancy is not selected; "The crowd was quiet. A girl whispered, "I hope it's not Nancy," [8] and the sound of the whisper reached the edges of the crowd". Girl's immediate reaction toward the incident shows the new generation having different opinions with regard to lottery in comparison with Old Man Warner. Besides, someone tells Mrs. Hutchinson that "over in the north village they're talking of giving up the lottery" [8]. This also shows that in some other places, people have been successful in freeing themselves from the system of mechanical solidarity. But still, within the society that the lottery takes place; people are led to give priority to collective personality rather than individual 
personality. In one part of the story, Mrs. Delacroix who is a friend of Mrs. Hutchinson is described throwing very big stones at Mrs. Hutchinson though a couple moments before they had a warm interaction with each other; "'Delacroix selected a stone so large she had to pick it up with both hands and turned to Mrs. Dunbar. 'Come on,' she said. 'Hurry up"' [8]. This can clearly shows individuals' lost aim and purpose with a higher aim called society.

Analyzing the story thoroughly, the part that most persistently attracted the attention of the people is the last part of the story when Mrs. Hutchinson is selected to be sacrificed for the society. Considering this sentence: "Although the villagers had forgotten the ritual and lost the original black box, they still remembered to use stones" [8], one can easily concludes that the nature of human being is totally corrupt and tended toward violence whereas from Durkheim's sociological perspective, the individuals are so much attached to the structure of the society that they are unable to totally free themselves from this highly intricate network of rules and regulations. The individual embedded in such system is unavoidably led forward to do the most horrific act. Through the rest of the story, the ceremony is described to be held as follows; "'The children had stones already. And someone gave little Davy Hutchinson few pebbles. It isn't fair, it isn't right,' Mrs. Hutchinson screamed, and then they were upon her'" [8]. Two critical points are manifested in this part, firstly the way someone gives few pebbles to little Davy Hutchinson to throw at her mother shows how each individual is trained to take steps with the path created by the society and secondly the way Mrs. Hutchinson is screaming that the act is totally unfair which shows that he is totally unwilling to what is happening to him. Mrs. Hutchinson should be really delighted to be selected as the one to be sacrificed for the sake of the society; nonetheless, she is considering it unfair. She is calling it as such because she is totally opposed to the basic nature of the society which gathers the people around; "one must therefore consider that he/she has no life of his own. Impersonality is here carried to its highest pitch" [2]. Hence, someone like her cannot be in line with the aim of society and is considering her right as an individual to live freely in the society. Seemingly, Amy A. Griffin who has analyzed Jackson's "The Lottery" has the same opinion while still not carrying Durkheim's sociological perspective:

At one point in the village's history, the lottery represented a grave experience, and all who participated understood the profound meaning of the tradition. But as time passed, the villagers began to take the ritual lightly. They endure it almost as automatons-"actors" anxious to return to their mundane, workaday lives. [9]

Durkheim defines altruistic suicide "to be symptomatic of the way in which the individual is structured into the society"[10]. His definition declares the extent to which the individual is situated within the structure of the society in past times that he/she willingly submit him/her self to be killed for the sake of the society. Such sacrifices never happen in the story because the individual is not going after the society's aim anymore and is aimed at setting certain set of ideals for him/her self. In this respect, readers usually misinterpret the meaning of altruistic suicide in the story as a mere act of savagely killing someone for nothing whereas in the past time as the society was not touched by any change, the individual would gladly submit him/her self to be sacrificed for the sake of the society and no one would consider it as an unjustified act. This should be emphatically noted that the act of killing Mrs. Hutchinson is never a barbaric and vicious act of killing someone whereas it is a sincere sacrifice for the society. Even, Shirley Jackson's comment upon the feedbacks she receives after publishing "The Lottery" is highlighting this fact:

Yet because of "The Lottery," Jackson says, "Millions of people, and my mother, had taken a pronounced dislike of me". There is no doubt some platform exaggeration in that statement, but Jackson's comment that "of the three-hundred-odd letters that I received that summer I can count only thirteen that spoke kindly to me, and they were mostly from friends" has the literal ring of truth. [6] 


\section{Conclusion}

Emile Durkheim opened a new perspective in considering the social relationships among the individuals forming a society. For Durkheim, society is the starting point that can affect the life of individuals. As such, he is mainly focused on the effect of rules and regulation generated by the society. Based on his observations, he extrapolates that traditional societies were predicated on mechanical solidarity while modern society is derived forward via the notion of organic solidarity. For Durkheim, mechanical solidarity shows human beings while being engaged in similar activities and relying mostly on shared beliefs and values instructed by the society. Durkheim's initial examination of the society was highly optimistic explaining how the individual is either fitted in the mechanical solidarity of traditional society or the organic solidarity of the modern society, nevertheless, when he wrote his seminal work, Suicide, he was completely focused on those abnormal situations created while either of these social bonds namely mechanical solidarity or organic solidarity is not working properly. One of Durkheim's decisive factors in determining the concept of suicide is the degree to which the individual is integrated with the society. Then he introduces two types of suicides namely altruistic and egoistic suicide. Durkheim believes that in traditional society as the individual is highly integrated within the society, he is tended toward committing altruistic suicide while the individual in modern world is more leaned toward egoistic suicide since he/she is highly disengaged from the society.

Approaching Shirley's Jackson's "The Lottery" from Durkheim's sociological perspective can be rewarding since Jackson's "The Lottery" is among one of the most favourite American short story ever written. However, most of the researches are focused on the devilish nature of human beings to devastate his/her own types. But in fact, approaching the short story from a sociological perspective can help us consider the story anew. This new perspective can contribute to the understanding of traditional societies. For Durkheim, an individual in traditional society is melted within the structure of the society and is directed toward whatever path, the society provides for him/her. Individual's ideal time is arrived when he has successfully achieved the goal which is defined by the society. The same thing is happening in "The Lottery". The story is about selecting one person from the people of the society to be sacrificed for the sake of the society. Though the one selected to be sacrificed should be really delighted about his/her selection but through the story, the selected one is sorrowful about her selection and bluntly expressing her discontent. From Durkheim's sociological perspective, the individuals are so much connected with the structure of the society that they are unable to totally free themselves from this highly intricate network of rules and regulations. Hence, this is concluded that the main character has indeed committed an altruistic suicide though seemingly he is brutally killed by his friends and family.

\section{Conflict of Interest}

The authors declare that there is no conflict of interest.

\section{References}

[1] E. Durkheim, Sociology and philosophy, Routledge, London, 2010.

[2] E. Durkheim, S. Lukes, W.D. Halls, The division of labour in society, Palgrave Macmillan, Basingstoke, 2013.

[3] M. Emirbayer, Introduction - Emile Durkheim: sociologist of modernity, Blackwell Publishing Ltd., 2003.

[4] K. Thompson, Emile Durkheim, Routledge, London, 1993.

[5] T. Thorlindsson, T. Bjarnason, Modeling Durkheim on the micro level: a study of youth suicidality, American Sociological Review. 63(1) (1998) 94-110.

[6] A. Charters, The story and its writer: an introduction to short fiction, Bedford/St. Martins, Boston, 2016. 
[7] A.R. Coulthard, Jackson's the Lottery, The Explicator. 48(3) (1990) 226-228.

[8] S. Jackson, The Lottery, Penguin Books, London, 2014.

[9] A.A. Griffin, Jackson's THE LOTTERY. The Explicator. 58(1) (1999) 44-46.

[10] E. Durkheim, K. Thompson, Readings from Emile Durkheim, Routledge, London, 2005. 